\title{
Oxaliplatin-Based Chemotherapy in Advanced Neuroendocrine Tumors: Clinical Outcomes and Preliminary Correlation with Biological Factors
}

\author{
Francesca Spada $^{a}$ Lorenzo Antonuzzo ${ }^{\text {e }}$ Riccardo Marconcini ${ }^{f}$ \\ Davide Radice $^{b}$ Andrea Antonuzzo ${ }^{f}$ Sergio Ricci $^{f}$ Francesco Di Costanzo $^{e}$ \\ Annalisa Fontanag ${ }^{9}$ Fabio Gelsomino ${ }^{g}$ Gabriele Luppig Elisabetta Nobili ${ }^{\text {h }}$ \\ Salvatore Galdy ${ }^{a}$ Chiara Alessandra Cella ${ }^{a}$ Angelica Sonzogni ${ }^{d} \quad$ Eleonora Pisac \\ Massimo Barberisc Nicola Fazio ${ }^{a}$ \\ ${ }^{a}$ Gastrointestinal Medical Oncology and Neuroendocrine Tumors Unit, ${ }^{b}$ Biostatistics and Epidemiology Department, \\ 'Histopathology and Molecular Diagnostics Unit, European Institute of Oncology, and d Fondazione IRCCS Istituto \\ Nazionale dei Tumori e Università degli Studi di Milano, Milan, ${ }^{e}$ Medical Oncology 1, AOU Careggi Hospital, \\ Florence, ${ }^{\mathrm{f}}$ Department of Oncology 2, University Hospital, Pisa, ${ }^{9}$ Department of Oncology and Hematology, General \\ Hospital, Modena, and hUOC of Oncology, General Hospital S. Orsola - Malpighi, Bologna, Italy
}

\section{Key Words}

Chemotherapy · Neuroendocrine tumor ·

Oxaliplatin - Pancreatic neuroendocrine tumors ·

Gastroenteropancreatic neuroendocrine tumors

\begin{abstract}
Purpose: The role of chemotherapy in low-/intermediategrade neuroendocrine tumors (NETs) is still debated. We present the results of an Italian multicenter retrospective study evaluating activity and toxicity of oxaliplatin-based chemotherapy in patients with advanced NETs. Methods: Clinical records from 5 referral centers were reviewed. Disease control rate (DCR) corresponding to PR + SD (partial response + stable disease) at 6 months, progression-free survival (PFS), overall survival (OS) and toxicity were calculated. Ki67 labeling index, grade of differentiation and excisionrepair-cross-complementing group 1 (ERCC-1) were analyzed in tissue tumor samples. Results: Seventy-eight patients entered the study. Primary sites were: pancreas in 46, gastro-
\end{abstract}

intestinal in 24, lung in 19 and unknown in $10 \%$ of patients. The vast majority were G2 (2010 WHO classification). Eightysix percent of the patients were metastatic, and $87 \%$ were pretreated and progressive to previous therapies. Sixty-five percent of the patients received capecitabine/oxaliplatin (CAPOX), 6\% gemcitabine/oxaliplatin (GEMOX), and 29\% leucovorin/fluorouracil/oxaliplatin (FOLFOX-6). PR occurred in $26 \%$ of the patients, half of them with pancreatic NETs, and SD in 54\%. With a median follow-up of 21 months, the median PFS and OS were 8 and 32 months with 70 and 45 events, respectively. The most frequent $\mathrm{G} 3$ toxicities were neurological and gastrointestinal. ERCC-1 immunohistochemical overexpression was positive in 4/28 evaluated samples, with no significant correlation with clinical outcome. Conclusion: This analysis suggests that oxaliplatin-based chemotherapy can be active with a manageable safety profile in advanced NETs irrespective of the primary sites and tumor grade. The 80\% DCR and 8-month PFS could justify a prospective study in NETs with intermediate biological characteristics, especially with pancreatic primary tumors.

(c) 2016 S. Karger AG, Basel

\section{KARGER}

E-Mail karger@karger.com

www.karger.com/nen
(C) 2016 S. Karger AG, Basel

0000-0000/16/1036-0806\$39.50/0
Nicola Fazio or Francesca Spada

Gastrointestinal Medical Oncology and Neuroendocrine Tumors Unit European Institute of Oncology, Via Ripamonti 435 IT-20141 Milan (Italy)

E-Mail nicola.fazio@ieo.it or francesca.spada@ieo.it 


\section{Introduction}

Neuroendocrine tumors (NETs) usually present as advanced, nonfunctioning and low/ intermediate grade of malignancy, and only in a minority of cases as high grade [1]. Though many NETs are clinically silent until late presentation with mass effect, they characteristically produce, store and secrete a variety of peptides and neuroamines, often leading to distinct clinical syndromes including carcinoid syndrome.

Gastroenteropancreatic NETs (GEP NETs) are classified on the basis of their proliferation rate, as assessed by either the mitotic index (MI) and/or nuclear Ki67 [2]. Low-grade or G1 are tumors with $0-2 \% \mathrm{Ki} 67$ and/or $<2$ MI per 10 high-power fields (HPF); intermediate-grade or G2 are tumors with 3-20\% Ki67 and/or 2-20 MI per $10 \mathrm{HPF}$, and high-grade or G3 are tumors with $>20 \%$ Ki67 and/or $>20$ MI per $10 \mathrm{HPF}$. The G1 and G2 are called NETs and G3 neuroendocrine carcinomas (NECs). This terminology is only valid for GEP NETs. According to the 2004 WHO classification [3], lung NETs are classified in: typical carcinoids (TCs), with $<2$ mitoses per $10 \mathrm{HPF}$ lacking necrosis; atypical carcinoids (ACs), with 2-10 mitoses per $10 \mathrm{HPF}$ and/or punctate necrosis; large-cell NECs (LCNECs), with >10 mitoses per $10 \mathrm{HPF}$ (median 70), coarse nuclear chromatin and extensive necrosis, and small-cell carcinomas (SCLCs) with $>10$ mitoses per 10 HPF (median 80), even chromatin and extensive necrosis.

Therapeutic options for NETs include local treatments such as surgery, as well as interventional radiology and systemic treatments, such as chemotherapy, somatostatin analogs (SSAs), interferon- $a 2 b$ (IFN-2b), peptide receptor radionuclide therapy (PRRT), and, only for pancreatic NET (PNET), molecular targeted agents including everolimus (EVE) and sunitinib (SUN).

So far, any high quality randomized controlled studies have shown the benefit of chemotherapy over best supportive care (BSC) in NET. In contrast, EVE and SUN proved efficacy, respectively, in progressive 'well-/moderately' and 'well-differentiated' PNET on the basis of 2 international multicenter randomized placebo-controlled phase III trials $[4,5]$. Moreover, octreotide LAR and lanreotide have shown efficacy in 'low' grade $1(\leq 2 \%$ Ki67, PROMID) [6] and grade $2(<10 \%$ Ki67, CLARINET) [7] midgut and nonfunctioning enteropancreatic neuroendocrine neoplasms (NENs), respectively, also in well-conducted phase 3 randomized controlled trials.

Focusing on chemotherapy, it is recommended in NECs of any site [8] and in PNET. Cisplatin-/carboplatin-based regimens are considered the mainstay of NECs and LCNECs/SCLCs [9], whereas a greater variability of choice exists regarding the other settings in which chemotherapy could have a role. Currently, streptozotocin, doxorubicin [10-13], temozolomide [14], 5-fluorouracil (5-FU) $[11,12]$, capecitabine (CAP) $[15,16]$, oxaliplatin [17-23] and gemcitabine (GEM) [18, 19] are still preferred in G2 PNETs and lung carcinoids, but to date there has not been a preferred regimen for G1/2 GEP NETs or TCs/aTCs universally shared yet.

Oxaliplatin is a platinum analogue with the same mechanism of action as those of the other platinum derivatives but with a different safety profile, known for its significant activity in several gastrointestinal (GI) cancers [20-25]. Platinum agents cause platinum-DNA adducts, leading to inter- and intrastrand crosslinks especially in highly proliferating cells. Unless these are repaired, the cell will undergo apoptotic death [26]. Nucleotide excision repair participates in the repair of platinum-induced DNA damage, with excision-repair-cross-complementing group 1 (ERCC-1) as one of several proteins involved, and it represents the rate-limiting protein in the process. ERCC-1 expression has been retrospectively associated with resistance against platinum-based chemotherapy in different types of cancer [26, 27]. A significantly higher expression of ERCC- 1 has been shown in TCs and ACs than in SCLCs. This finding suggests that the high expression of ERCC-1 in TCs might indicate the reason for failure of platinumbased chemotherapy in these patients and that ERCC-1 expression has a prognostic impact on lung carcinoids [28].

While oxaliplatin-based therapy has been reported to be active in NETs, although based on few studies (Appendix 1), no clinical and/or biological correlations with molecular factors are known so far. Based on this background, we studied this topic through a 'real world' analysis of patients treated in several Italian centers.

\section{Patients and Methods}

Study Design

This is a retrospective analysis of patients consecutively treated with oxaliplatin-based therapy from 1999 to 2013 selected from the NET databases of 5 Italian referral centers with particular expertise in the treatment of these rare tumors (European Institute of Oncology, Milano; Careggi Hospital, Firenze; Santa Chiara Hospital, Pisa; General Hospital, Modena, and S. Orsola-Malpighi General Hospital, Bologna).

\section{Patients and Tissue Specimens}

Key inclusion criteria were: age $>18$ years, histological diagnosis of NET, advanced stage, progressive to a prior therapy or early first diagnosis and ECOG (Eastern Cooperative Oncology Group) performance status $\leq 2$. Key exclusion criteria were: impaired car- 
diac function, severe liver or renal disease, inadequate bone marrow reserve and life expectancy $<3$ months. To minimize the risk of possible bias, histological diagnosis was confirmed by 3 pathologists with particular expertise in NENs (M.B., A.S., E.P.), who centrally (at the European Institute of Oncology) analyzed all tumor samples coming from surgical specimens or biopsies from metastatic sites, in order to evaluate the grade of differentiation, Ki67 and ERCC-1.

The Ki67 expression (LI) was assessed by counting the number of stained malignant cells, regardless of intensity, divided by the total number of malignant cells.

As for ERCC-1, formalin-fixed and paraffin-embedded material was used in the study. Briefly, 3- to 4-mm-thick sections were made to react with the relevant mouse monoclonal antibody to ERCC-1 (clone 8F1, dilution 1:100 for $30 \mathrm{~min}$ ) purchased from Aviva Systems Biology (San Diego, Calif., USA), and then incubated with a commercially available detection kit (EnVision ${ }^{\mathrm{TM}}$ FLEX+; Dako, Glostrup, Denmark) following the manufacturer's instructions. Results were rendered in a semiquantitative way as the percentage of immunoreactive cells, taking into account the entire tumor area on the paraffin blocks and the relevant nuclear compartmentalization representing the average intensity of the stained tumor cells $(0=$ no staining, $1=$ weak staining, $2=$ moderate staining, 3 = strong staining). Positive and negative controls were used as appropriate for ensuring accuracy of immunostaining.

All toxicity events were classified according to the National Cancer Institute Common Toxicity Criteria (NCI CTC) version 3.0 [29]. All patients provided written informed consent before starting chemotherapy according to the internal procedures of each institution.

\section{Study Treatment}

The CAPOX regimen consisted of intravenous (i.v.) administration of oxaliplatin $130 \mathrm{mg} / \mathrm{m}^{2}$ as a 2-hour i.v. infusion on day 1 followed by oral intake of CAP 2,000 $\mathrm{mg} / \mathrm{m}^{2}$ from day 1 to day 14 on a 3-weekly basis (q3w). The GEMOX provided GEM 1,000 mg/ $\mathrm{m}^{2}$ as a $30-\mathrm{min}$ i.v. infusion followed by oxaliplatin $100 \mathrm{mg} / \mathrm{m}^{2}$ as a 2-hour i.v. infusion q2w. The FOLFOX-6 regimen included 5-FU $85 \mathrm{mg} / \mathrm{m}^{2}$ as a 2-hour infusion (day 1), leucovorin $200 \mathrm{mg} / \mathrm{m}^{2}$ as an i.v. administration on day 1 followed by $5-\mathrm{FU} 400 \mathrm{mg} / \mathrm{m}^{2}$ as a bolus and 5-FU 2,400 $\mathrm{mg} / \mathrm{m}^{2}$ as a 46-hour infusion (days 1 and 2). All types of therapy were carried out until disease progression or unacceptable toxicity. Complete blood count, serum biochemistry and liver function tests were repeated $24-48 \mathrm{~h}$ before the first day of each treatment cycle. Drug safety was analyzed in all patients treated with at least 1 cycle. Chemotherapy was administered when the absolute peripheral granulocyte neutrophil count was $\geq 1,500$ / $\mathrm{mm}^{3}$ and the platelet count was $\geq 100,000 / \mathrm{mm}^{3}$. Chemotherapy doses were reduced if required according to the clinical practice at the physician's discretion.

Although this study had a retrospective design, and thus the follow-up program was not fully standardized, computed tomography $(\mathrm{CT})$ or magnetic resonance imaging assessments were suggested to be performed at baseline and at 3-month intervals after starting chemotherapy, and were evaluated according to the RECIST 1.0 criteria [30].

\section{Statistical Methods}

Patient characteristics, response to treatment and toxicity were summarized using either means, standard deviations, medians, ranges (continuous variables), or counts and percentages (categorical variables). Progression-free survival (PFS) was defined as the time from the date of cycle 1-day 1 of oxaliplatin-based chemotherapy to the date of neoplasm progression or death from any cause. Overall survival (OS) was defined as the time from the date of cycle 1-day 1 to the date of death from any cause. Ninety-five percent confidence intervals (CIs) for the disease control rate (DCR) were estimated using the binomial exact formula. Median PFS, median OS and survival curves were estimated by the KaplanMeier method and tabulated alongside their 95\% CIs. Survival curves were compared using the log-rank test. Hazard ratios were estimated using the Cox model with the Sidak adjustment for significant comparisons, as appropriate. Patients were considered evaluable if they received at least 1 cycle of chemotherapy. All tests were two sided and considered significant at the $5 \%$ level. All statistical analyses were conducted using SAS 9.3 (Cary, N.C., USA).

\section{Results}

\section{Patient Characteristics}

Baseline characteristics of the patients are reported in table 1. Primary tumor sites were: 36 pancreas (46\%), 19 GI (24\%), 15 lung (19\%) and 8 unknown (10\%). The GI NEN subgroup was almost entirely composed of small intestine (74\%). Among the 55 GEP, 10 were classified as G1, 36 G2 and 10 G3 according to the 2010 WHO classification. As for the 8 unknown primaries, 1 had $\mathrm{Ki} 67$ $\leq 2 \%$, $4 \mathrm{Ki} 67$ 3-20\%, $2 \mathrm{Ki} 67>20 \%$ and 1 was missing Ki67. Seven (5 pancreatic and 2 unknown primaries) out of the $13>20 \%$ Ki67 NENs had a well-differentiated morphology with $\mathrm{Ki} 67$ in the range of $21-55 \%$ (arbitrarily called 'low G3').

The 15 lung NENs were 2 TCs, 11 ACs, one LCNEC and one not otherwise specified according to the 2004 WHO lung NET classification. The mean Ki67 of the whole tumor population was $26.1 \%$ (IQR 5.0-20.0).

At the time of study treatment, $86 \%$ of patients had distant metastases, mainly in the liver. Among patients untreated at study entry, 30\% were PNET, 30\% GI, 20\% lung and $20 \%$ unknown primaries. All $87 \%$ of pretreated patients had radiological tumor progression to previous therapies, including chemotherapy $(47 \% ; 31 \%$ of them platinum based), liver-directed treatments (surgery, transarterial embolization, 37\%), SSAs \pm IFN (42\%), molecular targeted agents (23\%), and PRRT (23\%).

Among patients pretreated with platinum-based chemotherapy, $40 \%$ had PNET, 10\% GI, 30\% lung, and 20\% unknown primaries. Among the total of 476 full-dose cycles of oxaliplatin, the median cycle number per patient was 4.5 (range 1-9) for CAPOX, 3 (range 2-11) for GEMOX, and 7 (range 1-14) for FOLFOX-6. 
Table 1. Patient characteristics

\begin{tabular}{lc}
\hline Age at diagnosis, years & $54(25-79)$ \\
\hline Age at treatment start, years & $57(27-84)$ \\
\hline Time from diagnosis to treatment start, years & $2(0-13)$ \\
\hline Male gender & $47(60)$ \\
\hline Performance status (ECOG) & \\
0 & $70(90)$ \\
1 & $8(10)$ \\
\hline Site of primary tumor & \\
Pancreas & $36(46)$ \\
GI & $19(24)$ \\
Lung & $15(19)$ \\
Unknown & $8(10)$ \\
\hline Baseline status & \\
Pretreated & $68(87)$ \\
Untreated & $10(13)$ \\
\hline Grading & \\
GEP NET (2010 WHO Classification) & $55(70)$ \\
G1 & $10(18)$ \\
G2 & $36(65.5)$ \\
G3 & $10(18)$ \\
Unknown primary & $8(10)$ \\
Ki67 <2\% & $1(12.5)$ \\
Ki67 3-20\% & $4(50)$ \\
Ki67 $>20 \%$ & $2(25)$ \\
Unknown & $1(12.5)$ \\
Lung $(2004$ WHO classification) & $11(19)$ \\
Typical carcinoid & $1(7)$ \\
Atypical carcinoid & $1(7)$ \\
LCNEC & \\
NOS & \\
\hline & \\
Mean Ki67 (75/78) & \\
\hline
\end{tabular}

\begin{tabular}{lc}
\hline Mean Ki67 (75/78) & \\
All & $26.1 \%$ (IQR: $5.0-20.0)$ \\
Pancreas & $14.4 \%$ (IQR: $6.0-18.0)$ \\
GI & $66.8 \%$ (IQR: $4.0-70.0)$ \\
Lung & $18.2 \%$ (IQR: $3.0-20.0)$ \\
Unknown & $16.5 \%$ (IQR: $4.0-25.0)$ \\
\hline ERRC1 (28/78) & $4(14)$ \\
Positive & $24(86)$ \\
Negative & $11(14)$ \\
\hline Synchronous metastases & $38(49)$ \\
None & $21(27)$ \\
Hepatic & $8(10)$ \\
Extrahepatic & \\
Both & $56(72)$ \\
\hline Metachronous metastases & $5(6)$ \\
None & $1(1)$ \\
Hepatic & $16(21)$ \\
Extrahepatic & \\
Both & \\
\hline
\end{tabular}

\section{Clinical Outcomes}

There were no cases of complete response (CR). The objective tumor response rate $[\mathrm{CR}+$ partial response (PR)] was 26\%. The global DCR [PR + stable disease (SD)] at 6 months was $10.0 \%$ (95\% CI 3.7-20.5). Data about tumor response related to primary site subgroups and type of chemotherapy are reported in table 2. One patient with PNET received both FOLFOX and GEMOX regimen.

\section{Specific Subgroups}

The PR rate was 33\% in PNETs, $26 \%$ in GI, $13 \%$ in lung, and $13 \%$ in unknown primaries. Considering the grading of the GEP PR group, $10 \%$ were $\leq 2 \% \mathrm{Ki} 67,65 \%$ $3-20 \%$ and $15 \%>20 \%$. As for the lung PR group, $5 \%$ were ACs and 5\% LCNEC. Among the 13 patients with highgrade tumors ( $>20 \% \mathrm{Ki} 67 \mathrm{GEP} /$ unknown NETs or LCNECs), 38 had PR, $46 \mathrm{SD}$ and 15\% progressive disease (PD). Six out of the 7 well-differentiated NETs with 2155\% Ki67 ('low G3') had PR/SD.

The 12 PR patients with a PNET were almost all pretreated (mostly non-platinum-based chemotherapy). Among them, 4 patients received PRRT, but only 1 after a non-platinum-based chemotherapy regimen. As for GI setting, only 1 patient was pretreated with non-platinumbased chemotherapy; the other 4 patients were untreated. 


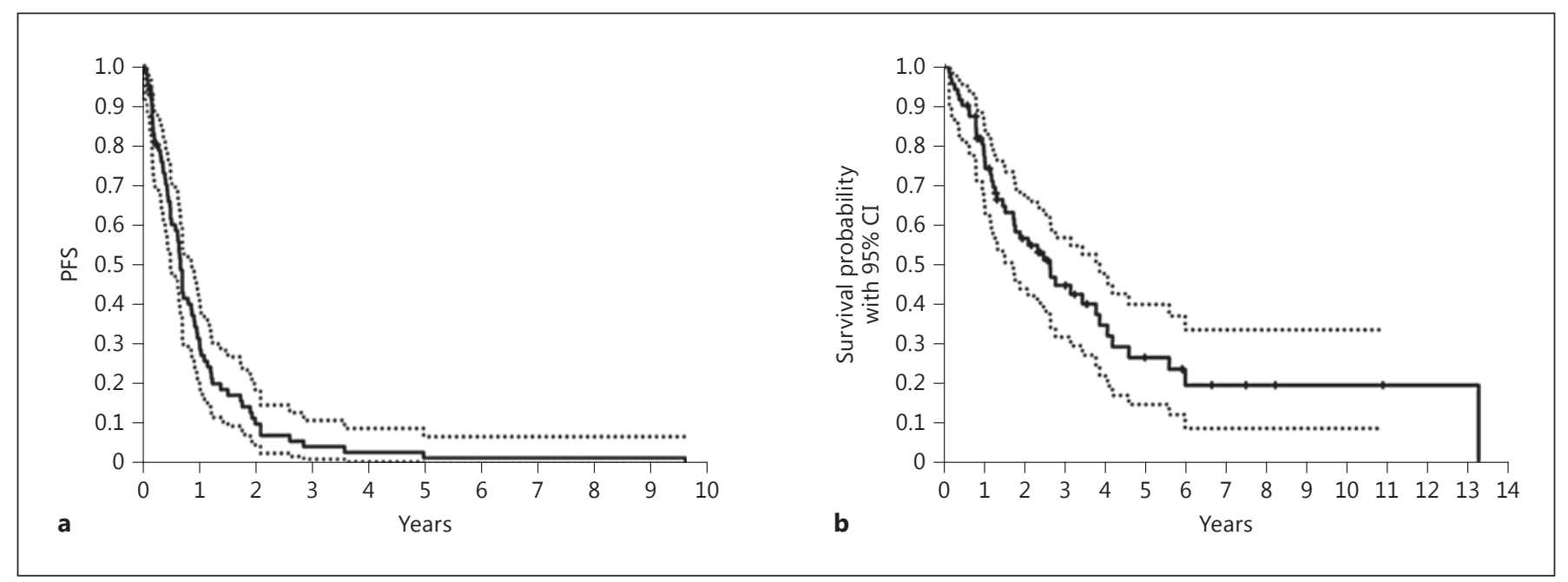

Fig. 1. a Kaplan-Meier curves for PFS, defined as time from cycle 1, day 1 until objective tumor progression or death due to any cause. b Kaplan-Meier curves for survival probability, defined as time from cycle 1, day 1 until death due to any cause.

Focusing on the untreated group, they had mostly SD $(70 \%)$, and they were GEP $(\mathrm{n}=4)$, lung $(\mathrm{n}=1)$ and unknown primary $(\mathrm{n}=1)$. On the other hand, the pretreated $\mathrm{PR}+\mathrm{SD}$ GEP NET group were mostly progressive to more than 2 systemic previous lines of therapy.

With a median follow-up of 21 months, the median PFS (fig. 1a) and OS (fig. 1b) were 8 and 32 months, with 70 and 45 events (tables 3,4 ).

At univariate analysis, the mPFS was significantly associated with grading $(\mathrm{p}=0.003$; table 3$)$. Moreover, a multivariable analysis was not performed because grading was the only statistically significant factor. However, the HR for OS and PFS were not statistically significant (tables 3, 4).

\section{Toxicity}

The most frequent grade 3-4 clinical toxicities per patient were peripheral neuropathy (10\%), diarrhea (6\%) and hematological neutropenia (3\%). The main hematological toxicity per cycle was nonfebrile neutropenia (3\%). Oxaliplatin discontinuation occurred in 2 patients due to hypersensitivity reaction: one after 11 GEMOX cycles and one after the first CAPOX cycle. There were no cases of toxic death.

\section{Immunohistochemical Analysis}

ERCC-1 was evaluated in 28/78 patients, based on the poor availability of biological materials. It was positive (strong staining) in 4 out of the 28 patients evaluated
Table 2. Activity and efficacy related to primary site

\begin{tabular}{lcclll}
\hline Outcome & $\begin{array}{l}\text { All } \\
(\mathrm{n}=78)\end{array}$ & $\begin{array}{l}\text { Pancreas } \\
(\mathrm{n}=36)\end{array}$ & $\begin{array}{l}\text { GI } \\
(\mathrm{n}=19)\end{array}$ & $\begin{array}{l}\text { Lung } \\
(\mathrm{n}=15)\end{array}$ & $\begin{array}{l}\text { Unknown } \\
(\mathrm{n}=8)\end{array}$ \\
\hline CR + PR & $20(26)$ & $12(33)$ & $5(26)$ & $2(13)$ & $1(13)$ \\
XELOX & $12(60)$ & $7(58)$ & $3(60)$ & $2(100)$ & 0 \\
FOLFOX & $6(30)$ & $3(25)$ & $2(40)$ & 0 & $1(100)$ \\
GEMOX & $2(10)$ & $2(17)$ & 0 & 0 & 0 \\
\hline SD & $42(54)^{\mathrm{a}}$ & $19(53)^{\mathrm{a}}$ & $7(37)$ & $10(67)$ & $6(75)$ \\
XELOX & $30(71)$ & $15(79)$ & $3(43)$ & $8(80)$ & $4(67)$ \\
FOLFOX & $11(26)$ & $4(21)$ & $4(57)$ & $1(10)$ & $2(33)$ \\
GEMOX & $2(5)$ & $1(10)$ & 0 & $1(10)$ & 0 \\
\hline PD & $14(18)$ & $4(11)$ & $6(32)$ & $3(20)$ & $1(12)$ \\
XELOX & $9(64)$ & $2(50)$ & $3(50)$ & $3(100)$ & $1(100)$ \\
FOLFOX & $4(29)$ & $1(25)$ & $3(50)$ & 0 & 0 \\
GEMOX & $1(7)$ & $1(25)$ & 0 & 0 & 0 \\
\hline NE & $2(2)$ & $1(3)$ & $1(5)$ & 0 & 0 \\
\hline PFS, months & 8 & & & & \\
\hline OS, months & 32 & & & & \\
\hline
\end{tabular}

Data are presented as number (\%). NE $=$ Not evaluable. ${ }^{\text {a }}$ One patient received both FOLFOX and GEMOX.

(14\%). Three out of 4 ERCC-1-positive neoplasms were PNETs, all G2 except for one G3 with Ki67 22\%, and the latter unknown primary. Three had received CAPOX, and 1 GEMOX with $1 \mathrm{PR}$ and $3 \mathrm{SD}$. 
Table 3. Median PFS and hazard ratio estimates by risk factors

Median PFS, years HR $(95 \% \mathrm{CI}) \quad$ Events/
(95\% CI) patients

Site of primary tumor

\begin{tabular}{llll} 
Pancreas & $0.81(0.63,1.10)$ & Ref & $35 / 36$ \\
Lung & $0.63(0.23,0.96)$ & $1.22(0.64,2.32)$ & $13 / 15$ \\
GI & $0.46(0.18,0.88)$ & $1.46(0.81,2.76)$ & $15 / 17$ \\
p value & & 0.427 & \\
\hline
\end{tabular}

\section{FDG PET-CT}

$\begin{array}{llll}\text { Yes } & 0.87(0.23,1.91) & - & 4 / 6 \\ \text { No } & 2.35(0.20,9.61) & - & 4 / 4 \\ \text { p value } & & \text { Not done } & \end{array}$

\begin{tabular}{llll}
\hline \multicolumn{2}{l}{ SRS/68-gallium PET-CT } & & \\
Yes & $0.67(0.40,0.96)$ & Ref & $23 / 24$ \\
No & $0.81(0.42,1.16)$ & $1.05(0.55,1.99)$ & $17 / 18$ \\
p value & & 0.891 & \\
\hline Grading & & & \\
ACs & $0.45(0.20,1.91)$ & Ref & $9 / 11$ \\
G1 & $0.38(0.06,0.44)$ & $4.31(1.41,13.2)$ & $6 / 7$ \\
G2 & $0.81(0.63,1.02)$ & $0.68(0.33,1.42)$ & $40 / 42$ \\
G3 & $0.79(0.13,1.04)$ & $1.04(0.42,2.60)$ & $10 / 10$ \\
p value & & $0.003^{\mathrm{a}}$ & \\
\hline
\end{tabular}

\begin{tabular}{lllc}
\multicolumn{2}{l}{ Synchronous metastases } & & \\
None & $0.45(0.08,1.51)$ & Ref & $9 / 11$ \\
Extrahepatic & $0.71(0.51,1.22)$ & $0.62(0.28,1.39)$ & $19 / 19$ \\
Extra + hepatic & $0.42(0.17,0.68)$ & $1.62(0.59,4.41)$ & $7 / 7$ \\
Hepatic & $0.71(0.50,0.93)$ & $0.77(0.36,1.62)$ & $35 / 38$ \\
p value & & 0.184 & \\
\hline Metachronous metastases & & \\
None & $0.71(0.50,0.93)$ & Ref & $51 / 53$ \\
Extrahepatic & $0.66(0.41,1.10)$ & $1.13(0.62,2.06)$ & $14 / 16$ \\
Extra + hepatic & 0.08 & - & $1 / 1$ \\
Hepatic & $0.71(0.12,1.02)$ & $1.74(0.62,4.90)$ & $4 / 5$ \\
p value & & 0.556 & \\
\hline
\end{tabular}

\begin{tabular}{ccll}
\hline \multicolumn{2}{l}{ Previous chemotherapy } & & \\
No & $0.65(0.45,0.86)$ & Ref & $40 / 43$ \\
Yes & $0.71(0.44,0.98)$ & $1.13(0.69,1.86)$ & $29 / 31$ \\
p value & & 0.625 & \\
\hline Ki67 & - & $1.00(0.86,1.16)^{\mathrm{b}}$ & \\
p value & & 0.974 & \\
\hline Overall PFS & $0.68(0.50,0.88)$ & - & $70 / 75$ \\
\hline
\end{tabular}

$\mathrm{HR}=$ Hazard ratio; Ref = reference category $\mathrm{CI}=$ confidence interval; FDG PET-CT = fluorodeoxyglucose positron emission tomography-CT; SRS = somatostatin receptor scintigraphy; 68-gallium PET-CT $=$ positron emission tomography-CT with 68 gallium DOTATOC radiolabeled somatostatin analog. ${ }^{\text {a }}$ Significant comparisons (with Sidak adjustment): G1 vs. G2, p = 0.013; G1 vs. ACs, $p=0.01{ }^{b}$ By unit increase.
Table 4. Median OS time and hazard ratio estimates by risk factors

Median OS, years HR $(95 \% \mathrm{CI}) \quad$ Events/
$(95 \% \mathrm{CI})$ patients

Site of primary tumor

\begin{tabular}{lllr} 
Pancreas & $2.64(1.26,4.17)$ & Ref & $23 / 36$ \\
Lung & $1.77(0.63,3.86)$ & $1.60(0.73,3.53)$ & $9 / 13$ \\
GI & $1.74(0.79,-)$ & $1.02(0.47,2.21)$ & $9 / 18$ \\
p value & & 0.427 & \\
\hline
\end{tabular}

\begin{tabular}{llll}
\hline $\begin{array}{l}\text { FDG PET-CT } \\
\text { Yes }\end{array}$ & Not reached & - & \\
No & $3.86(1.89,-)$ & - & $2 / 7$ \\
p value & & Not done & $2 / 4$ \\
\hline
\end{tabular}

\begin{tabular}{llll}
\hline \multicolumn{2}{l}{ SRS/68-gallium PET-CT } & & \\
Yes & $2.63(1.21,4.17)$ & Ref & $17 / 23$ \\
No & $1.74(0.95,2.76)$ & $1.05(0.55,1.99)$ & $10 / 19$ \\
p value & & 0.891 & \\
\hline
\end{tabular}

\section{Grading}

\begin{tabular}{lllc} 
Atypical & $1.76(0.12,-)$ & Ref & $7 / 10$ \\
G1 & $5.98(0.16,-)$ & $0.47(0.11,1.93)$ & $3 / 8$ \\
G2 & $3.43(1.74,5.58)$ & $0.46(0.19,1.11)$ & $24 / 43$ \\
G3 & $1.18(0.45,4.58)$ & $1.06(0.38,2.96)$ & $8 / 10$ \\
p value & & 0.128 & \\
\hline
\end{tabular}

Synchronous metastases

\begin{tabular}{lllc} 
None & $2.64(0.63,3.76)$ & Ref & $6 / 11$ \\
Extrahepatic & $3.31(1.16,5.58)$ & $0.97(0.37,2.55)$ & $14 / 21$ \\
Extra + hepatic & $1.01(0.26,1.21)$ & $3.54(0.94,13.4)$ & $4 / 8$ \\
Hepatic & $2.46(1.74,4.58)$ & $0.81(0.32,2.07)$ & $21 / 35$ \\
p value & & 0.102 & \\
\hline
\end{tabular}

\begin{tabular}{lllc}
\hline \multicolumn{2}{l}{ Metachronous metastases } & & \\
None & $2.76(1.52,4.58)$ & Ref & $30 / 54$ \\
Extrahepatic & $3.76(0.98,4.17)$ & $1.11(0.55,2.23)$ & $11 / 15$ \\
Extra + hepatic & 1.26 & - & $1 / 1$ \\
Hepatic & $2.62(0.12,2.66)$ & $1.49(0.45,4.97)$ & $3 / 5$ \\
p value & & 0.795 &
\end{tabular}

Previous chemotherapy

\begin{tabular}{rlll} 
No & $2.46(1.21,4.58)$ & Ref & $26 / 44$ \\
Yes & $2.76(1.52,4.17)$ & $0.95(0.52,1.73)$ & $19 / 30$ \\
p value & & 0.873 & \\
\hline Ki67 & - & $1.12(0.94,1.34)^{\mathrm{a}}$ & \\
p value & & 0.974 & \\
\hline OS & $2.63(1.72,3.86)$ & - & $45 / 75$ \\
\hline
\end{tabular}

$\mathrm{HR}=$ Hazard ratio; FDG PET-CT = fluorodeoxyglucose positron emission tomography-CT; SRS = somatostatin receptor scintigraphy; 68-gallium PET-CT = positron emission tomographyCT with 68 gallium DOTATOC radiolabeled somatostatin analog; Ref $=$ reference category; $\mathrm{CI}=$ confidence interval. ${ }^{\text {a }}$ By unit increase. 


\section{Discussion}

Even in a 'real-world' setting and in heavily pretreated patients, the $80 \%$ DCR, and the 8 - and 32-month PFS and OS, respectively, with a manageable toxicity profile, seem to support the role of oxaliplatin-based chemotherapy as an effective therapeutic option for these rare malignancies.

In NECs, cisplatin/etoposide is the most commonly proposed regimen based on the assumption that the clinical behavior of NECs is similar to that of SCLCs $[9,10$, $28,31,38,39]$. In GEP NETs and lung carcinoids, various data have demonstrated a significant anticancer activity mainly using alkylating agents as streptozotocin $[10,11$, $13,40-42]$, and temozolomide [14] and some nonalkylating agents, such as doxorubicin [8], epirubicin, 5-FU, CAP [11-13, 43], oxaliplatin [17] and GEM [18, 19], but so far there has been no globally shared standard chemotherapy. In PNETs, although some experience has been reported, the specific role of chemotherapy is still unknown in patients with G1-2 PNETs progressive on EVE or SUN $[4,5]$, or in PNETs with some negative prognostic factors, such as positive fluorodeoxyglucose positron emission tomography-computed tomography [32] or high Ki67 [33]. In GI non-PNETs, lung carcinoids and 'low-grade' NECs (Ki67 <55\%), chemotherapy has a less defined role $[34,35,37]$.

Furthermore, the correct timing of chemotherapy related to EVE in NETs is currently under investigation in a two-arm randomized phase III trial (SEQTOR study. EUDRACT No.: 2013-000726-66).

Recently, few studies with oxaliplatin-based chemotherapy have been published in this setting $[17,18,36$, 37] with quite a low total number of patients, and there have been some other studies presented at the main meetings (Appendix 1). To our knowledge, our study is the largest series reported so far after a recently published French study on 104 patients treated with GEMOX [36]. Similarly to the others, our series included a mixed NET population; therefore, this feature could represent a limit of our study due to different biology, genetic features and expected outcome depending on different primary tumor sites, tumor differentiation and role of pretreatment. As in the 4 published studies [17-19, 36, 37], GEP NETs were the most frequent, of which PNETs were the most common. Similar to the French series, we reported the DCR detailed for primary sites, showing that PNETs were more sensitive to oxaliplatin-based chemotherapy compared to GI non-PNETs and the other primary tumors.
Our study included low- and high-grade NETs, but in contrast with the other studies we reported a more detailed tumor characterization (differentiation and Ki67). In particular, the study by Bajetta et al. [17] was only based on the 2000 WHO classification (tumor differentiation) and Ferrarotto et al. [37] reported three groups of patients (named G1, G2 and G3), but specific data regarding Ki67, correlation with tumor morphology and classification references are missing. Dussol et al. [19] reported a grading system in terms of morphology as originally described for GEP NETs. The $80 \%$ overall DCR of our study overlaps with those of the studies by Dussol et al. [19] and Bajetta et al. [17] with 81 and 62\%, respectively.

Despite the increasing number of therapeutic options for patients with PNET, the higher level of evidence achieved for some of them over the last decades and the availability of multiple guidelines published by the major societies engaged with this disease, a clear rationale on the most appropriate medical sequence of treatments is still lacking, and it seems to be mostly arbitrary.

Although we cannot clearly define the role of the previous treatment in our population due to the retrospective nature of our study, the heterogeneity and the poorness of the sample, the lower PD and the higher PR rate in the pretreated group versus the untreated one (14 vs. $26 \%$ and 31 vs. $13 \%$, unlike the other studies) signify that the previous treatments may have affected our results. However, neither the OS nor PFS were significantly affected.

The responsive pretreated GEP NET group of our series was progressive on 2 or more lines of therapy; therefore, it might be suggested to administer an oxaliplatinbased chemotherapy after previous systemic treatments.

The above-mentioned studies lack a common biological predictive factor which could help clinicians to select potential responders to this therapy.

Some data show a better survival for ERCC-1-positive patients in TC and AC as compared with ERCC-1-negative patients, but no data exist for GEP NETs so far. However, because of a low number of included patients and a low number of events, the authors concluded that these results should be confirmed in larger studies.

In our report, ERCC-1 expression resulted predominantly negative in the $86 \%$ of patients in whom it was evaluated; therefore, its contribution to the clinical outcomes in our patients is unclear. Despite the lack of a full review of tissue specimens, we suggest further evaluating the potential predictive role of ERCC-1 as an interesting clue to response criteria. 
Although no definitive conclusions can be drawn from our series of patients due to its retrospective nature and heterogeneity of tumors, oxaliplatin-based chemotherapy seems to be active in patients with advanced NETs, irrespective of the primary site and biology. These results warrant a prospective trial with a homogenous clinical and biological NET population, including a biological study on the potential predictive role of ERCC-1 with a reproducible method.

\section{Acknowledgements}

The authors thank Ms. Kimberley Davies for revising the English, Dr. Luca Giacomelli for his writer revision and Prof. Giuseppe Pelosi for his suggestions.

\section{Disclosure Statement}

The authors do not have any conflicts of interest to declare.

Appendix 1. Trials with oxaliplatin-based chemotherapy in NENs by year of publication (mixed tumor population for each study).

\begin{tabular}{lllllllll}
\hline First author [Ref.] & $\begin{array}{l}\text { Publication } \\
\text { year }\end{array}$ & Regimen & $\begin{array}{l}\text { Study } \\
\text { type }\end{array}$ & $\begin{array}{l}\text { Patients, } \\
\mathrm{n}\end{array}$ & $\begin{array}{l}\text { PR } \\
\%\end{array}$ & $\begin{array}{l}\text { SD } \\
\%\end{array}$ & $\begin{array}{l}\text { PFS, } \\
\text { months }\end{array}$ & $\begin{array}{l}\text { OS, } \\
\text { months }\end{array}$ \\
\hline Bajetta [17] & 2007 & XELOX & Phase II & 40 & 27.5 & 35 & 18 & 32 \\
Pape [20] & 2006 & FOLFOX & R & 16 & None & 62 & 4 & NR \\
Venook [21] & 2008 & FOLFOX6 + BEV & Phase II & 13 & 40 & 60 & NR & NR 19 \\
Cassier [18] & 2009 & GEMOX & R & 20 & 17 & 67 & 7 & 23 \\
Kunz [22] & 2010 & XELOX + BEV & Phase II & 40 & 23 & 71 & 13.7 & - \\
Ferrarotto [37] & 2013 & XELOX & R & 24 & 29 & 71 & 9.8 & NR \\
Dussol [19] & 2015 & GEMOX & R & 104 & 23 & 60 & 7.8 & 31.6 \\
Walter [36] & 2015 & GEMOX & R & 44 & 17 & 69 & 14 & 35 \\
& & FOLFOX & & & & & & \\
\hline
\end{tabular}

$\mathrm{R}=$ Retrospective; $\mathrm{NR}=$ not reached; XELOX = xeloda/oxaliplatin; FOLFOX = leucovorin/fluorouracil/oxaliplatin; $\mathrm{BEV}=$ bevacizumab; GEMOX = gemcitabine/oxaliplatin.

\section{References}

1 Modlin IM, Kidd M, Latich I, Zikusoka MN, Shapiro MD: Current status of gastrointestinal carcinoids. Gastroenterology 2005;128:17171751.

2 Bosman FT, Carneiro F, Hruban RH, Thiese N (eds): World Health Organization Classification of Tumours. Pathology and Genetics. Tumors of the Digestive System. Lyon, IARC Press, 2010.

3 Travis WD, Brambilla E, Muller-Hermelink HK, Harris CC: Pathology and Genetics of Tumors of the Lung, Pleura, Thymus and Heart. Geneva, IARC Press, 2004.

-4 Yao JC, Shah MH, Ito T, Bohas CL, Wolin EM, Van Cutsem E, Hobday TJ, Okusaka T, Capdevila J, de Vries EG, Tomassetti P, Pavel ME, Hoosen S, Haas T, Lincy J, Lebwohl D, Öberg K; RAD001 in Advanced Neuroendocrine Tumors, Third Trial (RADIANT-3) Study Group. Everolimus for advanced pancreatic neuroendocrine tumors. N Eng J Med 2011;364:514523.

5 Raymond E, Dahan L, Raoul JL, Bang YJ, Borbath I, Lombard-Bohas C, Valle J, Metrakos P, Smith D, Vinik A, Chen JS, Hörsch D, Hammel
P, Wiedenmann B, Van Cutsem E, Patyna S, Lu DR, Blanckmeister C, Chao R, Ruszniewski P: Sunitinib malate for the treatment of pancreatic neuroendocrine tumors. $\mathrm{N}$ Eng J Med 2011;364:501-513.

- 6 Rinke A, Müller HH, Schade-Brittinger C, Klose KJ, Barth P, Wied M, Mayer C, Aminossadati B, Pape UF, Bläker M, Harder J, Arnold C, Gress T, Arnold R; PROMID Study Group: Placebo-controlled, double-blind, prospective, randomized study on the effect of octreotide LAR in the control of tumor growth in patients with metastatic neuroendocrine midgut tumors: a report from the PROMID Study Group. J Clin Oncol 2009;27:4656-4663.

7 Caplin ME, Pavel M, Cwikla JB, Phan AT, Sedlackova E, Cadio G, Wolin EM, Capdevilla J, Wall L, Rindi G, Langley A, Martinez S, Blumberg J, Ruszniewski P; CLARINET Investigators: Lanreotide in metastatic enteropancreatic neuroendocrine tumors. N Engl J Med 2014; 371:224-233.

8 Falconi M, Bartsch DK, Eriksson B, Klöppel G, Lopes JM, O'Connor JM, Salazar R, Taal BG, Vullierme MP, O’Toole D: Barcelona Consen- sus Conference participants. ENETS Consensus Guidelines for the management of patients with digestive neuroendocrine neoplasms of the digestive system: well-differentiated pancreatic non-functioning tumors. Neuroendocrinology 2012;95:120-134.

-9 Moertel CG, Kvols LK, O’Connell MJ, Rubin J: Treatment of neuroendocrine carcinomas with combined etoposide and cisplatin. Evidence of major therapeutic activity in anaplastic variance of these neoplasms. Cancer 1991; 68:227-232.

10 Sun W, Lipsitz S, Catalano P, Mailliard JA, Haller DG: Phase II/III study of doxorubicin with fluorouracil compared with streptozocin with fluorouracil or dacarbazine in the treatment of advanced carcinoid tumors: Eastern Cooperative Oncology Group Study E1281. J Clin Oncol 2005;23:4897-4904.

11 Kouvaraki MA, Ajani JA, Hoff P, Wolff R, Evans DB, Lozano R, Yao JC: Fluorouracil, doxorubicin, and streptozocin in the treatment of patients with locally advanced and metastatic pancreatic endocrine carcinomas. J Clin Oncol 2004;22:4762-4771. 
12 Delaunoit T, Ducreux M, Boige V, Dromain C, Sabourin JC, Duvillard P, Schlumberger M, de Baere T, Rougier P, Ruffie P, Elias D, Lasser P, Baudin E: The doxorubicin-streptozotocin combination for the treatment of advanced well-differentiated pancreatic endocrine carcinoma; a judicious option? Eur J Cancer 2004; 40:515-520.

-13 Fjällskog ML, Janson ET, Falkmer UG, Vatn MH, Öberg KE, Eriksson BK: Treatment with combined streptozotocin and liposomal doxorubicin in metastatic endocrine pancreatic tumors. Neuroendocrinology 2008;88:53-58.

14 Strosberg JR, Fine RL, Choi J, Nasir A, Coppola D, Chen DT, Helm J, Kvols L: First-line chemotherapy with capecitabine and temozolomide in patients with metastatic pancreatic endocrine carcinomas. Cancer 2011;117:268-275.

- 15 Brizzi MP, Berruti A, Ferrero A, Milanesi E, Volante M, Castiglione F, Birocco N, Bombaci S, Perroni D, Ferretti B, Alabiso O, Ciuffreda L, Bertetto O, Papotti M, Dogliotti L: Continuous 5-fluorouracil infusion plus long-acting octreotide in advanced well-differentiated neuroendocrine carcinomas. A phase II trial of the Piemonte Oncology Network. BMC Cancer 2009;9:388.

16 Berruti A, Fazio N, Ferrero A, Brizzi MP, Volante M, Nobili E, Tozzi L, Bodei L, Torta M, D’Avolio A, Priola AM, Birocco N, Amoroso V, Biasco G, Papotti M, Dogliotti L: Bevacizumab plus octreotide and metronomic capecitabine in patients with metastatic wellto-moderately differentiated neuroendocrine tumors: the XELBEVOCT study. BMC Cancer 2014; $14: 184$.

17 Bajetta E, Catena L, Procopio G, De Dosso S, Bichisao E, Ferrari L, Martinetti A, Platania M, Verzoni E, Formisano B, Bajetta R: Are capecitabine and oxaliplatin (XELOX) suitable treatments for progressing low-grade and high-grade neuroendocrine tumors? Cancer Chemother Pharmacol 2007;59:637-642.

$\checkmark 18$ Cassier PA, Walter T, Eymard B, Ardisson P, Perol M, Paillet C, Chayvialle JA, Scoazec JY, Hervieu V, Bohas CL: Gemcitabine and oxaliplatin combination chemotherapy for metastatic well-differentiated neuroendocrine carcinomas. Cancer 2009;115:3392-3399.

-19 Dussol AS, Joly MO, Vercherat C, Forestier J, Hervieu V, Scoazec JY, Lombard-Bohas C, Walter T: Gemcitabine and oxaliplatin or alkylating agents for neuroendocrine tumors: comparison of efficacy and search for predictive factors guiding treatment choice. Cancer 2015;121:3428-3434.

20 Pape U, Tiling N, Bartel C, Plöckinger U, Wiedenmann B: Oxaliplatin plus 5-fluorouracil/ folinic acid as palliative treatment for progressive malignant gastrointestinal neuroendocrine carcinomas (abstract 14074). ASCO Annu Meet, Atlanta, June 2006.

21 Venook AP, Ko AH, Tempero M, Uy J, Weber T, Korn M, Bergsland EK: Phase II trial of FOLFOX plus bevacizumab in advanced, progressive neuroendocrine tumors (abstract 15545). ASCO Annu Meet, Chicago, MayJune 2008.
22 Kunz PL, Kuo T, Zahn H, Kaiser HL, Norton JA, Visser BC, Longacre TA, Ford JM, Balise RR, Fisher GA: A phase II study of capecitabine, oxaliplatin, and bevacizumab for metastatic or unresectable neuroendocrine tumors (abstract 4104). ASCO Annu Meet, Chicago, June 2010.

23 de Gramont A, Figer A, Seymour M, Homerin M, Hmissi A, Cassidy J, Boni C, Cortes-Funes H, Cervantes A, Freyer G, Papamichael D, Le Bail N, Louvet C, Hendler D, de Braud F, Wilson C, Morvan F, Bonetti A: Leucovorin and fluorouracil with or without oxaliplatin as first-line treatment in advanced colorectal cancer. J Clin Oncol 2000;18:2938-2947.

24 Cunningham D, Starling N, Rao S, Iveson T, Nicolson M, Coxon F, Middleton G, Daniel F, Oates J, Norman AR; Upper Gastrointestinal Clinical Studies Group of the National Cancer Research Institute of the United Kingdom: Capecitabine and oxaliplatin for advanced esophagogastric cancer. N Engl J Med 2008; 358:36-46.

25 André T, Tournigand C, Rosmorduc O, Provent S, Maindrault-Goebel F, Avenin D, Selle F, Paye F, Hannoun L, Houry S, Gayet B, Lotz JP, de Gramont A, Louvet C; GERCOR Group: Gemcitabine combined with oxaliplatin (GEMOX) in advanced biliary tract adenocarcinoma: a GERCOR study. Ann Oncol 2004;15:1339-1343.

26 Rabik CA, Dolan ME: Molecular mechanisms of resistance and toxicity associated with platinating agents. Cancer Treat Rev 2007;33:9-23.

27 Martin LP, Hamilton TC, Schilder RJ: Platinum resistance: the role of DNA repair pathways. Clin Cancer Res 2008;14:1291-1295.

28 Skov BG, Holm B, Erreboe A, Skov T, Mellemgaard A: ERCC1 and Ki67 in small cell lung carcinoma and other neuroendocrine tumors of the lung: distribution and impact on survival. J Thorac Oncol 2010;5:453-459.

29 Cancer Therapy Evaluation Program, Common Terminology Criteria for Adverse Events, version 3.0, 2003.

30 Therasse P, Arbuck SG, Eisenhauer EA, Wanders J, Kaplan RS, Rubinstein L, Verweij J, Van Glabbeke M, van Oosterom AT, Christian MC, Gwyther SG: New guidelines to evaluate the response to treatment in solid tumors. European Organization for Research and Treatment of Cancer, National Cancer Institute of the United States, National Cancer Institute of Canada. J Natl Cancer Inst 2000;92:205-216.

-31 Mitry E, Baudin E, Ducreux M, Sabourin JC, Rufié P, Aparicio T, Aparicio T, Lasser P, Elias D, Duvillard P, Schlumberger M, Rougier P: Treatment of poorly differentiated neuroendocrine tumours with etoposide and cisplatin. Br J Cancer 1999;81:1351-1355.

32 Binderup T, Knigge U, Loft A, Federspiel B, Kjaer A: ${ }^{18} \mathrm{~F}$-fluorodeoxyglucose positron emission tomography predicts survival of patients with neuroendocrine tumors. Cancer Res 2010;16:978-985.
33 Scarpa A, Mantovani W, Capelli P, Beghelli S, Boninsegna L, Bettini R, Panzuto F, Pederzoli P, delle Fave G, Falconi M: Pancreatic endocrine tumors: improved TNM staging and histopathological grading permit a clinically efficient prognostic stratification of patients. Mod Pathol 2010;23:824-833.

34 Crona J, Fanola I, Lindholm DP, Antonodimitrakis P, Öberg K, Eriksson B, Granberg D: Effect of temozolomide in patients with metastatic bronchial carcinoids. Neuroendocrinology 2013;98:151-155.

35 Ekeblad S, Skogseid B, Dunder K, Öberg K, Eriksson B: Prognostic factors and survival in 324 patients with pancreatic endocrine tumor treated at a single institution. Clin Cancer Res 2008; 14:7798-7803.

36 Walter T, Planchard D, Bouledrak K, Guigay J, Dussol AS, Scoazec JY, Hervieu V, Ducreux M, Lombard Boas C, Baudin E: Evaluation of the combination oxaliplatin and 5-fluorouracil or gemcitabine in patients with metastatic lung carcinoid tumors (abstract J12). ENETS Annu Conf, Barcelona, March 2015.

- 37 Ferrarotto R, Testa L, Riechelmann RP, Sahade M, Siqueira LT, Costa FP, Hoff PM: Combination of capecitabine and oxaliplatin is an effective treatment option for advanced neuroendocrine tumors. Rare Tumors 2013;5:e35.

- 38 Iwasa S, Morizane C, Okusaka T, Ueno H, Ikeda M, Kondo S, Tanaka T, Nakachi K, Mitsunaga S, Kojima Y, Hagihara A, Hiraoka N: Cisplatin and etoposide as first-line chemotherapy for poorly differentiated neuroendocrine carcinoma of the hepatobiliary tract and pancreas. Jpn J Clin Oncol 2010;40:313-318.

39 Fjällskog MLH, Granberg DPH, Welin SLW, Eriksson C, Öberg KE, Janson ET, Eriksson BK: Treatment with cisplatin and etoposide in patients with neuroendocrine tumors. Cancer 2001;92:1101-1107.

40 Ridolfi R, Amaducci L, Derni S, Fabbri L, Innocenti MP, Vignutelli P: Chemotherapy with 5 -fluorouracil and streptozocin in carcinoid tumors of gastrointestinal origin: experiences with 13 patients. J Chemother 1991;3:328-331.

41 Dahan L, Bonnetain F, Rougier P, Raoul JL, Gamelin E, Etienne PL, Cadiot G, Mitry E, Smith D, Cvitkovic F, Coudert B, Ricard F, Bedenne L, Seitz JF; Fédération Francophone de Cancérologie Digestive (FFCD); Digestive Tumors Group of the Fédération Nationale des Centres de Lutte Contre le Cancer (FNCLCC): Phase III trial of chemotherapy using 5-fluorouracil and streptozotocin compared with interferon alpha for advanced carcinoid tumors: FNCLCC-FFCD 9710. Endocr Relat Cancer 2009;16:1351-1361.

42 Rivera E, Ajani JA: Doxorubicin, streptozotocin, and 5-fuorouracil chemotherapy for patients with metastatic islet-cell carcinoma. Am J Clin 1998;21:36-38.

43 Bajetta E, Rimassa L, Carnaghi C, Seregni E, Ferrari L, Di Bartolomeo M, Regalia E, Cassata A, Procopio G, Mariani L: 5-Fluorouracil, dacarbazine, and epirubicin in the treatment of patients with neuroendocrine tumors. Cancer 1998;83:372-378 